\title{
XXX. A new table of the quantities of acid in sulphuric acid of different densities, constructed for the use of manufacturers; being the result of experiments made with the strongest sulphuric acid of commerce. The specific gravities taken at the temperature of $60^{\circ}$
}

\section{Samuel Parkes F.L.S.}

To cite this article: Samuel Parkes F.L.S. (1812) XXX. A new table of the quantities of acid in sulphuric acid of different densities, constructed for the use of manufacturers; being the result of experiments made with the strongest sulphuric acid of commerce. The specific gravities taken at the temperature of $60^{\circ}$, Philosophical Magazine Series 1, 40:173, 161-168, DOI: $\underline{10.1080 / 14786441208638209}$

To link to this article: http://dx.doi.org/10.1080/14786441208638209

Published online: 27 Jul 2009.

Submit your article to this journal $\llbracket$

Џll Article views: 2 


\section{$\left[\begin{array}{ll}161 & ]\end{array}\right.$}

XXX. A New Talle of the Quantities of Acid in Sulphuric Acid of different Densities, constructed for the Use of Manufacturers; being the Result of Experiments made with the strongest Sulphuric Acid of Commerce. The specific Gravities taken at the Temperature of $60^{\circ}$. By Samuel Parkes, F.L.S.

\section{To Mr. Tilloch.}

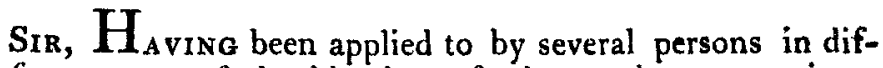
ferent parts of the kingdom, for instructions respecting a mode of ascertaining the quantity of acid in diluted sulphuric acid, I invariably referred them to Dr. Kirwan's Table, which was published in the year 1793 in the fourth volume of the Transactions of the Royal Irish Academy. This however always proved unsatisfactory, inasmuch as few manufacturers understood how to accommodate that table to the common oil of vitriol, or make it applicable to any practical purpose. This has arisen from the circumstance of Dr. Kirwan having taken sulphuric acid, as it exists in sulphate of potass, instead of the strongest oil of vitriol, for his standard of real acid. Having, in my own business, found the inconvenience of this, 1 several years ago formed a Table for my private use, from the sulphuric acid of commerce, by diluting that acid with several successive portions of water; a table which I have ever since employed with great advantage. But as this table was formed at a temperature above the mean temperature of the atmosphere, and its range was too confined to be of use in every instance, I resolved to undertake the formation of a new one that would be more generally useful, and that should descend by regular gradations down to the lowest point of dilution that any consumer of sulphuric acid would be likely to require *. Having now, at no small expense of time and labour, completed this Table, I shall be obliged if you will have the goodness to insert it in the next Philosophical Magazine, as I conceive that it will be acceptable and useful to many individuals in various branches of trade and manufacture.

In making this table, I might have taken purified sulphuric acid, i.e. such as bad undergone a second distillation; but as this is an article which is never employed but for philosophical purposes, I thought it better to make use of the

* The first line of the Table shows the specific gravity of a mixture of one part water and 100 parts of strong sulphuric acid. The latter, the specific gravicy of one part of sulphuric acid mixed with 100 parts of water. Vol. 40. No.173. Sept. 1812. L common 
common acid, and to take as good a sample of that kind as I could possibly procure. I have therefore chosen some of my own manufacture, made in the usual way, and con. centrated, as is common in large manufactories, by steaming it in a boiler of lead, and finishing it in a retort of glass. When I began the experiment, the atmosphere of the room was at $60^{\circ} *$, and the acid was of the specific gravity of

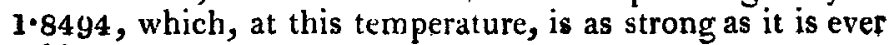
sold.

In order to form the annexed Table, I proceeded as follows :

I first accurately weighed ten thousand grs. of this acid into a stoppered bottle of glass, and then added to it $\mathbf{1 0 0}$ grains of pure watert. When the mixture was become cool, after having been sufficiently agitated, the specific gravity of it was taken, and the result forms the first line of the Table. In this way I continued to dilute the acid with successive portions of water, taking care to let it rest a sufficient time between each addition of the water, that a complete union between the acid and the water might take place; having found by experiment that a mixture of sulphuric acid and water, even after it has become cold, requires several hours for it to arrive at the maximum of condensation. I took also the precaution of keeping it in stoppered bottles, that it might not imbibe water from the atmosphere, and frequently agitated it during each interval. And, in order to attain as great accuracy as possible, I procured a gravity bottle larger than usual, one that holds nearly ten ounces of water, and with a stem so small that at the part to which the fluid rises when properly filled, a single drop of the liquor will occasion a rise of nearly one sixteenth of an inch.

- The halance which 1 made use of in these experiments, is so delicate that it will turn with the 20 th part of a grain; and as the acids will erode the common scale-dishes, if dropt upon them, and endanger the accuracy of a result, I have long been in the habit of using those made with Wedgwood's ware, and such were employed in making this Table. Thuse parts of the Table which have a star opposite to them, were made by actual experiment-the intermediate ones were the results of calculation.

- For the difference which is occasioned in the specific gravity of sul phpric acid by change of temperature, consult Nicholson's Journal, quarto, vol. iii. page 211 .

$f$ In diluting sulphuric acid, it is usual, and safer, to add the acid by degrees to the water, and not the water to the acid; but with this very small quantity of water, such caution was not necessary.

Since 
Since I concluded these experiments it occurred to me, that it might be useful to some manufacturers to know the quantity of acid per cent. in diluted acid of any given strength; I have therefore calculated the quantity in each, and annexed it. The column of ounces and drachms is added for the use of those who are accustomed to this mode of reckoning, and also for those who are not conversant with the usual method of stating specific gravities; and is calculated on the supposition of the wine pint holding exactly sixteen ounces avoirdupois of pure water*.

The sulphuric acid which is consumed in these kingdoms amounts I believe to upwards of three thousand tons annually; the greater part of which is used in a state of dilution. For the purposes of dissolving iron or zinc, it should be diluted with at least five or six times its weight of water. Sulphuric acid is consumed in large quantities by bleachers, for making the oxymuriate of lime, and these people always use it in a state of dilution. The calico printers also expend large sums in the purchase of this acid, which they use in various states of dilution, for making what they call sours.

To these, and other manufacturers, this Table will be of use, not only in assisting them in the formation of acid of any given strength, but it will enable them at any time to ascertain whether their servants have observed due care in making the different preparations; which is a matter of great moment-for it often happens, that for want of this the printer and manufacturer suffer great loss, and the goods sustain an irreparable injury.

I need scarcely add that the oil of vitriol-makers themselves, may also derive great benefit from attending to this Table.

$$
\begin{aligned}
& \text { I am, sir, yours, \&c. } \\
& \begin{array}{c}
\text { Goswell-street Chemical Works, } \\
\text { London, Sept. 2, 1812. }
\end{array} \\
& \text { SAMUEt PARKes. }
\end{aligned}
$$

* It is a convenient way of measuring, to have a glass bottle with a narrow neck, holding rather more than a pint of water, with a mark on the stem exactly at the place to which the water ascends when it contains exactly 16 ounces avoirdupois of that fluid. It was formerly understood that the standard wine pint was the exact measure of 16 ounces of pure water; but some experiments made in the year 1688, before the Lord Mayor and the Board of Excise, decided, that the sealed wine gallon of Guildhall contains only 224 cubic inches, though by the fifth of Qieen Ann, chap. vii. $\$ 7$, it is called 231 inches. This decision makes the wine pint to hold only 970 of an avoirdupois pound of water; but as it is generally thought right, for all common purposes still to consider it of the capacity of 16 ounces avoirdupois, I have taken it at that in this instance. 


\section{[ 164 ]}

A Table of the Specific Gravities of Sulphuric Acid, when diluted with different Portions of Water, at the Temperature $60^{\circ}$.

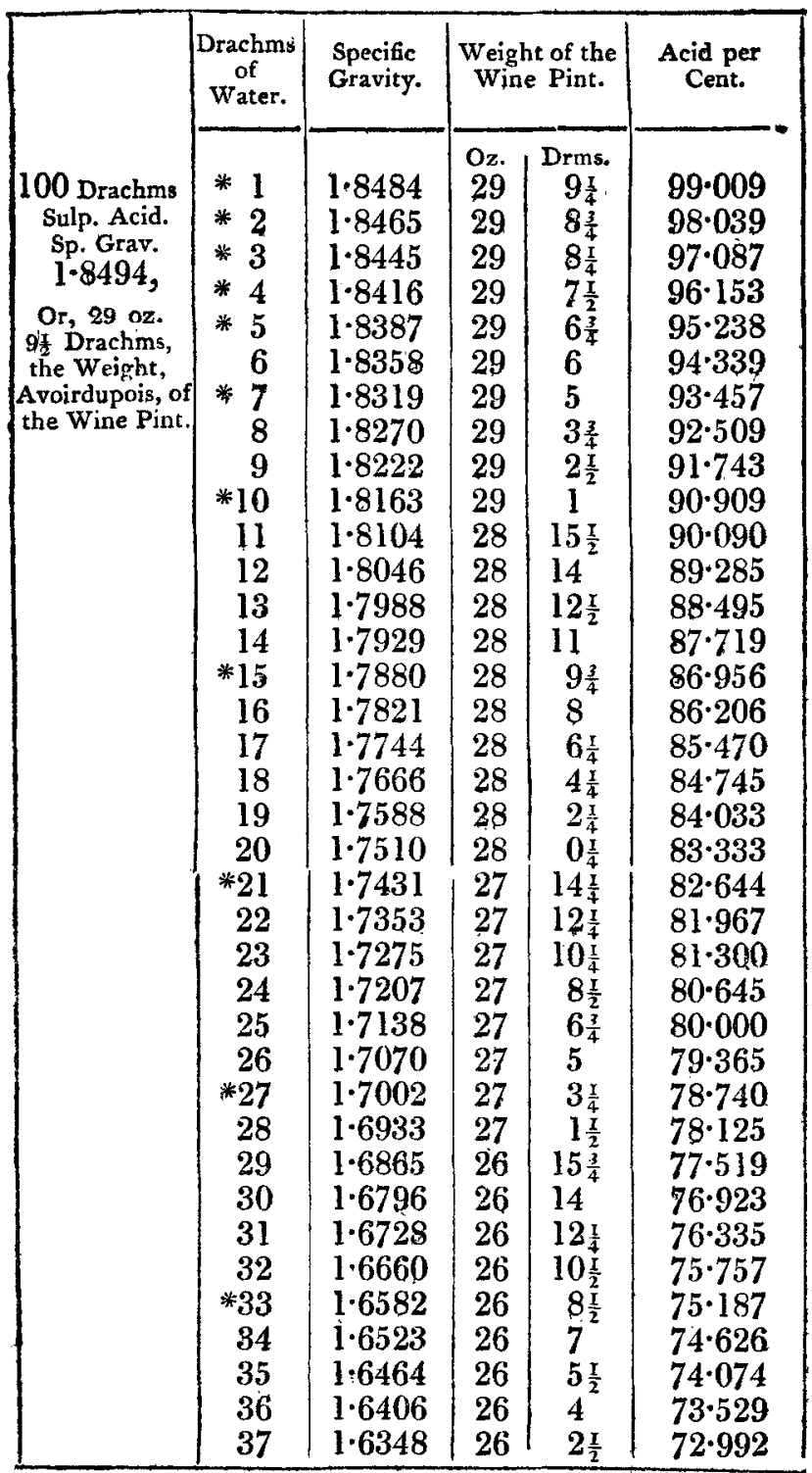


A Talle of the Specific Grautities of Sulphiric Actd. 165

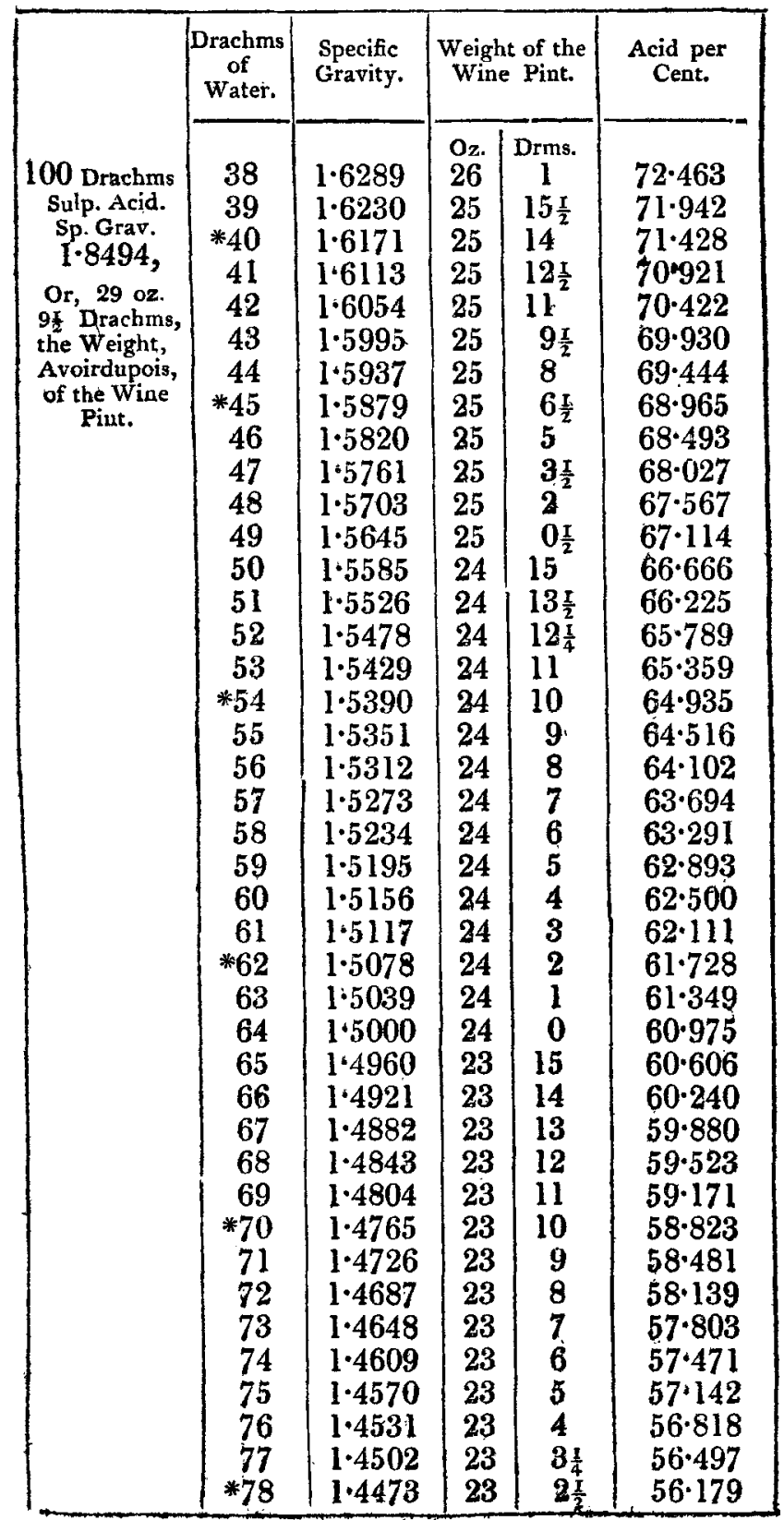


166 A Table of the Specific Gravities of Sulphuric Acid.

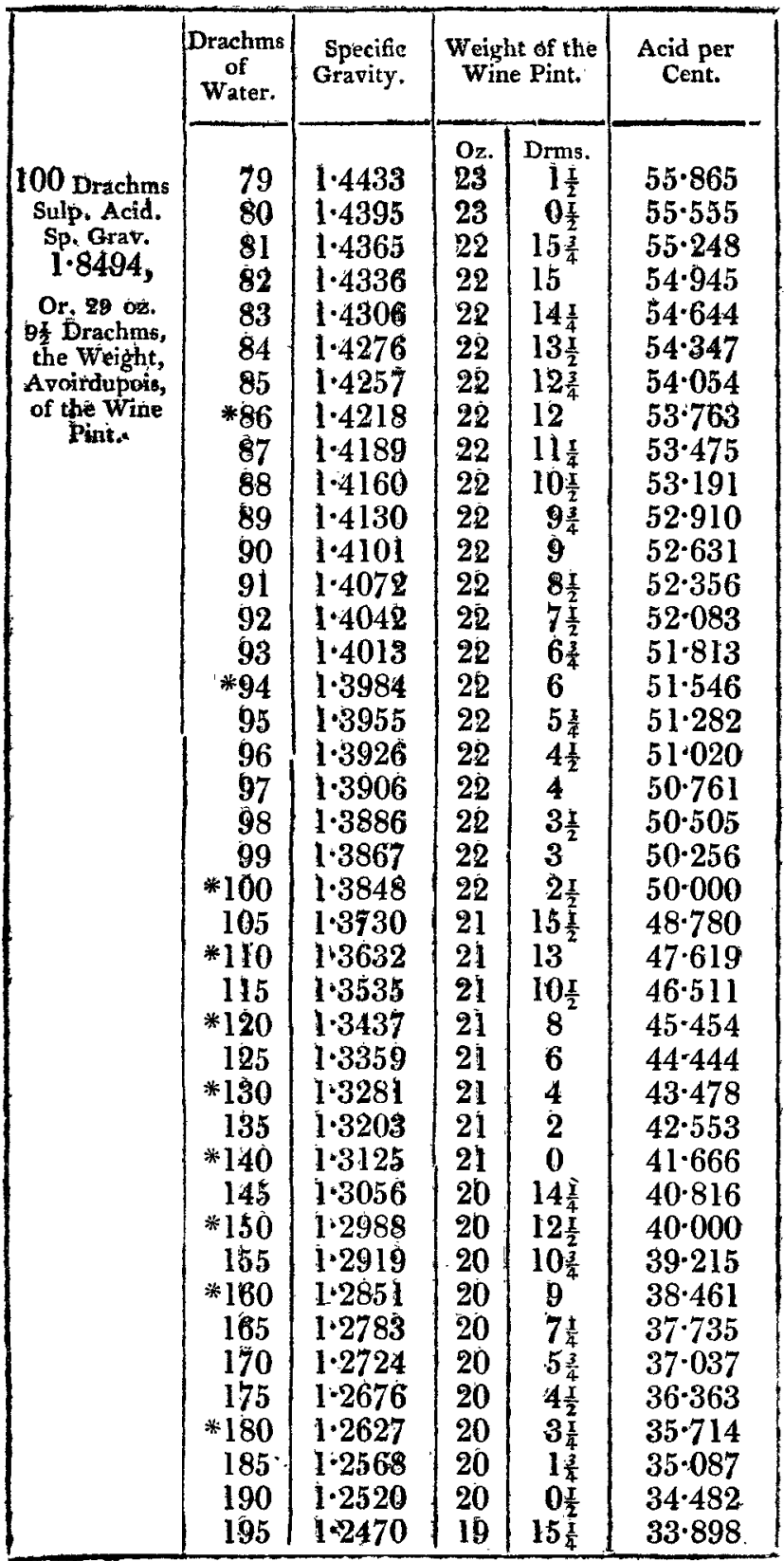


A Table of the Specific Gravities of Sulphuric Acid. 167

\begin{tabular}{|c|c|c|c|c|c|}
\hline \multirow{42}{*}{$\begin{array}{l}100 \text { Drachms } \\
\text { Sulp. Acid. } \\
\text { Sp. Grav. } \\
1.8494 \text {, } \\
\text { Or, } 29 \text { oz. } \\
91 \text { Drachms, } \\
\text { the Weight, } \\
\text { Avoirdupois, } \\
\text { of the Wine } \\
\text { Pint. }\end{array}$} & \multirow{2}{*}{$\begin{array}{c}\begin{array}{c}\text { Drachms } \\
\text { of } \\
\text { Water. }\end{array} \\
* 200\end{array}$} & \multirow{2}{*}{$\begin{array}{l}\text { Specific } \\
\text { Gravity. } \\
1 \cdot 2421\end{array}$} & \multicolumn{2}{|c|}{$\begin{array}{l}\text { Weight of the } \\
\text { Wine Pint. }\end{array}$} & \multirow{2}{*}{$\begin{array}{c}\begin{array}{c}\text { Acid per } \\
\text { Cent. }\end{array} \\
33 \cdot 333\end{array}$} \\
\hline & & & $\begin{array}{l}\text { Oz. } \\
19\end{array}$ & $\begin{array}{l}\text { Drms. } \\
14\end{array}$ & \\
\hline & 210 & $1 \cdot 2343$ & 19 & 12 & $32 \cdot 258$ \\
\hline & $* 220$ & $1 \cdot 2265$ & 19 & 10 & $31 \cdot 250$ \\
\hline & 230 & $1 \cdot 2187$ & 19 & 8 & $30 \cdot 303$ \\
\hline & $* 240$ & $1 \cdot 2129$ & 19 & $6 \frac{1}{2}$ & $29 \cdot 411$ \\
\hline & 250 & $1 \cdot 2060$ & 19 & $4 \frac{3}{4}$ & 28.571 \\
\hline & $* 260$ & $1 \cdot 1992$ & 19 & 3 & $27 \cdot 777$ \\
\hline & 270 & $1 \cdot 1933$ & 19 & $1 \frac{\mathrm{I}}{2}$ & $27 \cdot 027$ \\
\hline & $* 280$ & $1 \cdot 1875$ & 19 & $0^{2}$ & 26.315 \\
\hline & 290 & $1 \cdot 1825$ & 18 & $14 \frac{3}{4}$ & $25 \cdot 641$ \\
\hline & $* 300$ & $\mathrm{i} \cdot 1776$ & 18 & $13 \frac{1}{2}$ & $25 \cdot 000$ \\
\hline & 310 & $1 \cdot 1728$ & 18 & $12 \frac{\frac{z}{4}}{4}$ & $24 \cdot 390$ \\
\hline & 320 & $1 \cdot 1679$ & 18 & 11 & $23 \cdot 809$ \\
\hline & 330 & $1 \cdot 1630$ & 18 & $9 \frac{3}{4}$ & $23 \cdot 255$ \\
\hline & $* 340$ & $1 \cdot 1582$ & 18 & $8 \frac{1}{2}$ & $22 \cdot 727$ \\
\hline & 350 & $1 \cdot 1552$ & 18 & $7 \frac{2}{4}$ & $22 \cdot 222$ \\
\hline & 360 & $1 \cdot 1523$ & 18 & $7^{4}$ & $21 \cdot 739$ \\
\hline & 370 & $1 \cdot 1494$ & 18 & $6 \frac{1}{4}$ & $21 \cdot 276$ \\
\hline & $* 380$ & $1 \cdot 1464$ & 18 & $5 \frac{1}{2}$ & $20 \cdot 833$ \\
\hline & 390 & $1 \cdot 1426$ & 18 & $4 \frac{1}{2}$ & $20 \cdot 408$ \\
\hline & 400 & $1 \cdot 1338$ & 18 & $2 \frac{\pi}{4}$ & $20 \cdot 000$ \\
\hline & $* 420$ & $1 \cdot 1328$ & 18 & 2 & $19 \cdot 230$ \\
\hline & 440 & $1 \cdot 1279$ & 18 & $0 \frac{3}{4}$ & 18.518 \\
\hline & $* 460$ & $1 \cdot 1240$ & 17 & $15 \frac{3}{4}$ & $17 \cdot 857$ \\
\hline & 480 & $1 \cdot 1181$ & 17 & $14 \frac{4}{4}$ & $17 \cdot 241$ \\
\hline & $* 500$ & $1 \cdot 1132$ & 17 & 13 & $16 \cdot 666$ \\
\hline & *550 & $1 \cdot 1054$ & 17 & 11 & $15 \cdot 384$ \\
\hline & $* 600$ & $1 \cdot 0966$ & 17 & $8 \frac{3}{4}$ & $14 \cdot 285$ \\
\hline & *650 & $\mathrm{I} \cdot 0898$ & 17 & 7 & $13 \cdot 333$ \\
\hline & *700 & $1 \cdot 0839$ & 17 & $5 \frac{1}{2}$ & $12 \cdot 500$ \\
\hline & *750 & $1 \cdot 0781$ & 17 & $4^{4}$ & $11 \cdot 764$ \\
\hline & *800 & 1.0732 & 17 & $2 \frac{3}{4}$ & $11 \cdot 111$ \\
\hline & $* 850$ & $1 \cdot 0693$ & 17 & $1 \frac{3}{4}$ & $10 \cdot 526$ \\
\hline & $* 900$ & $1 \cdot 0664$ & 17 & 1 & $10 \cdot 000$ \\
\hline & $* 950$ & $1 \cdot 0625$ & 17 & 0 & 9.523 \\
\hline & $* 1000$ & $1 \cdot 0602$ & 16 & $15 \frac{1}{2}$ & 0.090 \\
\hline & 1100 & 1.0546 & 16 & 14 & 8333 \\
\hline & 1200 & 1.0507 & 16 & 18 & $7 \cdot 692$ \\
\hline & $* 1300$ & $1 \cdot 0488$ & 16 & $12 \frac{1}{2}$ & $7 \cdot 142$ \\
\hline & $* 1400$ & $1 \cdot 0458$ & 16 & 114 & $6 \cdot 666$ \\
\hline & $* 1500$ & $1 \cdot 0429$ & 16 & 11 & 6250 \\
\hline
\end{tabular}


An Account of some Experiments on the

\begin{tabular}{|c|c|c|c|c|c|}
\hline \multirow{4}{*}{\begin{tabular}{|c} 
\\
100 Drachms \\
Sulp. Acid. \\
Sp. Grav. \\
1.8494.
\end{tabular}} & \multirow{2}{*}{\begin{tabular}{|c}
$\begin{array}{c}\text { Drachms } \\
\text { of } \\
\text { Water. }\end{array}$ \\
1600
\end{tabular}} & \multirow{2}{*}{$\begin{array}{r}\text { Specific } \\
\text { Gravtiy. } \\
1 \cdot 0390\end{array}$} & \multicolumn{2}{|c|}{$\begin{array}{l}\text { Weight of the } \\
\text { Wine Pint. }\end{array}$} & \multirow{2}{*}{$\begin{array}{c}\begin{array}{c}\text { Acid per } \\
\text { Cent. }\end{array} \\
5.882\end{array}$} \\
\hline & & & $\begin{array}{l}\text { Oz. } \\
16\end{array}$ & $\begin{array}{l}\text { Drms. } \\
10\end{array}$ & \\
\hline & 1700 & 1.0370 & 16 & $9 \frac{1}{2}$ & 5.555 \\
\hline & *1800 & $1 \cdot 0351$ & 16 & 9 & $5 \cdot 263$ \\
\hline 1.8494 & 1900 & $1 \cdot 0337$ & 16 & 85 & $5 \cdot 000$ \\
\hline Or, 29 oz. & $* 2000$ & 1.0322 & 16 & $8 \frac{1}{4}$ & $4 \cdot 761$ \\
\hline $\begin{array}{l}9 \frac{1}{2} \text { Drachms, } \\
\text { the Weight, }\end{array}$ & $* 2250$ & 1.0283 & 16 & $7 \frac{4}{4}$ & $4 \cdot 255$ \\
\hline Avoirdupois, & *2500 & $1 \cdot 0254$ & 16 & $6 \frac{4}{2}$ & $3 \cdot 846$ \\
\hline of the Wine & $* 2750$ & $1 \cdot 0234$ & 16 & 6 & $3 \cdot 508$ \\
\hline & $* 3000$ & $1 \cdot 0214$ & 16 & $5 \frac{1}{2}$ & $3 \cdot 225$ \\
\hline & *3500 & $1 \cdot 0185$ & 16 & $4 \frac{3}{4}$ & $2 \cdot 777$ \\
\hline & $* 4000$ & $1 \cdot 0166$ & 16 & $4 \frac{1}{4}$ & $2 \cdot 439$ \\
\hline & $* 4500$ & $1 \cdot 0146$ & 16 & $3 \frac{3}{4}$ & $2 \cdot 173$ \\
\hline & *5000 & $1 \cdot 0127$ & 16 & $3 \frac{4}{4}$ & $1 \cdot 960$ \\
\hline & 5500 & 1.0117 & 16 & $3^{4}$ & $1 \cdot 785$ \\
\hline & $* 6000$ & 1.0107 & 16 & $2 \frac{3}{4}$ & $1 \cdot 639$ \\
\hline & 6500 & $1 \cdot 0102$ & 16 & $2 \frac{5}{8}$ & 1.515 \\
\hline & $* 7000$ & 1.0098 & 16 & $2 \frac{1}{2}$ & $1 \cdot 408$ \\
\hline & 7500 & $1 \cdot 0093$ & 16 & $2 \frac{3}{8}$ & $1 \cdot 315$ \\
\hline & $* 8000$ & $1 \cdot 0088$ & 16 & $2 \frac{1}{4}$ & $1 \cdot 234$ \\
\hline & 8500 & $1 \cdot 0083$ & 16 & $2 \frac{1}{8}$ & $1 \cdot 162$ \\
\hline & $* 9000$ & $1 \cdot 0078$ & 16 & $2^{8}$ & $1 \cdot 098$ \\
\hline & 9500 & $1 \cdot 0073$ & 16 & $1 \frac{7}{8}$ & $1 \cdot 041$ \\
\hline & $* 10000$ & $1 \cdot 0068$ & 16 & $1 \frac{3}{4}$ & 0.990 \\
\hline
\end{tabular}

XXXI. AnAccount of some Experiments on the Combinations of different Metals and Chlorine, \&8c. By Joнn DavY, Esq. Communicated by Sir HumphrY DavY, Knt. LL.D. SeE. R.S.

[Concluded from p. 91.]

5. On the Relation between the Proportion of Oxygen and Chlorine in Combination with several Metals.

$\mathbf{E}_{\text {RRors being very common in chemical analyses, even }}$ in those conducted most skilfully and carefully, all possible means should be taken to discover them; and no means, I think, promise to be more effectual for this purpose, than the general analogy of definite proportions. From a great variety of facts, it appears that oxygen and chlorine combine with bodies in the ratio of 7.5 to 33.6 . With one 